\title{
Rare PTA variant (Saltzman type IIla) associated with multiple cerebral aneurysms
}

\author{
Odai Abdalla, ${ }^{1}$ Rashid Ahmed, ${ }^{1}$ Amr Ewida, ${ }^{1}$ Grahame Gould ${ }^{2}$
}

${ }^{1}$ Neurology, SUNY Upstate Medical University, Syracuse, New York, USA

${ }^{2}$ Neurosurgery, SUNY Upstate Medical University, Syracuse, New York, USA

\section{Correspondence to Dr Rashid Ahmed: Ahmedra@upstate.edu}

Accepted 21 February 2021

\section{DESCRIPTION}

A 68-year-old woman with a history of hypertension, hyperlipidemia and 10 pack-year smoking history presented with sudden onset of the worst headache of her life. She denied any family history of brain aneurysms. CT angiography (CTA) revealed a subarachnoid haemorrhage due to a ruptured right posterior communicating artery ( $\mathrm{P} \mathrm{Comm})$ aneurysm $(6.8 \times 6.7 \mathrm{~mm})$ with a small temporal lobe haematoma adjacent to the right P Comm artery aneurysm dome (figure 1). She underwent a cerebral angiogram that demonstrated multiple aneurysms, including an anterior communicating artery (A Comm) aneurysm $(7.8 \times 3.8 \mathrm{~mm})$, left posterior cerebral artery aneurysm $(4 \times 2.5 \mathrm{~mm})$ and anterior choroidal artery aneurysm $(1.4 \times 0.5 \mathrm{~mm})$. A persistent trigeminal artery (PTA) originating from the lacerum portion of the right internal carotid artery (ICA) was incidentally noted on catheter angiogram (figure 2). The PTA originated from the lateral aspect of the right ICA before coursing towards the posterior fossa where it supplied the superior portion of the right cerebellum. Diffuse, irregular appearance of the cerebrovascular system, consistent with advanced atherosclerotic disease, was also noted on angiography. The patient underwent coil embolization of the right P Comm aneurysm. After uncomplicated embolization of the $\mathrm{P}$ Comm aneurysm, she developed concordant ECG and haemodynamic changes. The embolization of the A Comm aneurysm was aborted for urgent cardiovascular evaluation. Her hospital course was further complicated by delayed cerebral ischaemia requiring aggressive medical and endovascular treatment. The patient was discharged to a rehab
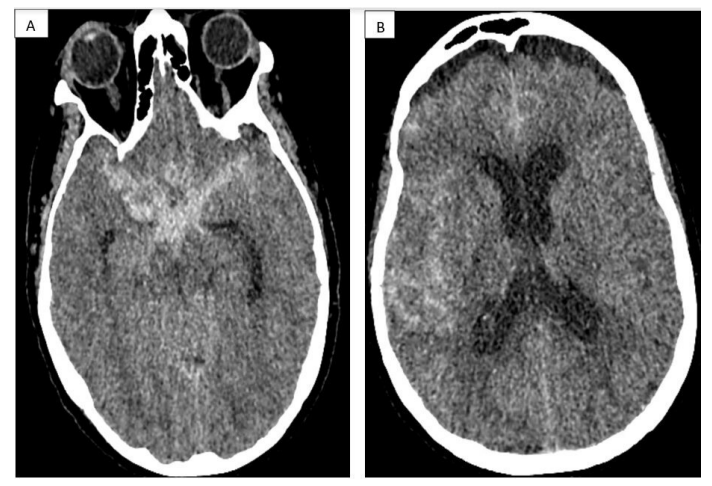

Figure $1 C T$ of the head $(A, B)$ revealed extensive acute blood in the basal, suprasellar cisterns and subarachnoid spaces along both cerebral convexities, right greater than the left. There was a component of intraparenchymal haemorrhage in the right medial temporal lobe.
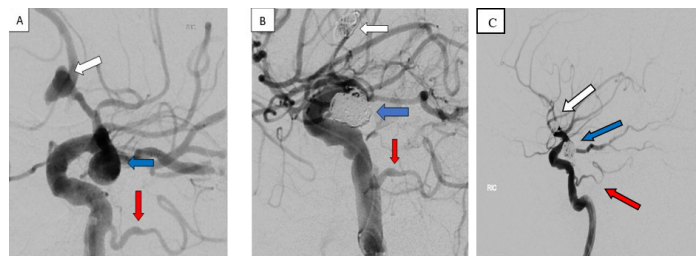

Figure 2 Digital subtraction angiogram. (A) Right P Comm aneurysm, before coiling (blue arrow); A Comm aneurysm, before coiling (white arrow); and PTA (red arrow). (B) Right P Comm aneurysm, after coiling (blue arrow); A Comm aneurysm, after coiling (white arrow); and PTA (red arrow). (C) Right P Comm aneurysm, after coiling (blue arrow); A Comm aneurysm, after coiling (white arrow); and PTA originating from the lacerum portion of the right internal carotid artery (red arrow). A Comm, anterior communicating artery; P Comm, posterior communicating artery; PTA, persistent trigeminal artery.

facility after a complicated hospital course. She was cleared by cardiology for the treatment of A Comm aneurysm. The patient was admitted electively 2 months later, and the A Comm aneurysm was successfully treated with stent-assisted coil embolization. The patient was discharged on dual antiplatelet therapy. The patient was seen 2 weeks later through telemedicine clinic visit and was doing well. She is scheduled for a repeat catheter angiogram 6 months after her A Comm aneurysm embolization.

Park et $a l^{1}$ reviewed 3552 cerebral angiograms, and five cases of PTA variants (incidence of $0.14 \%$ ) were noted, among which only one case was a Saltzman type IIIa variant (incidence of $0.02 \%$ ). Uchino $e t a l^{2}$ reported the incidence of PTA variant (Saltzman type III) to be approximately $0.18 \%$ on digital subtraction angiogram (DSA) and $0.76 \%$ on MR angiography. Siqueira et $a l^{3}$ reviewed 5500 angiographic studies over 4 years and found 11 cases of PTA variant (incidence of $0.18 \%$ ). Shoja et $a l^{4}$ reported a case of a 52-year-old white woman who presented with headache and subarachnoid haemorrhage; CTA revealed no aneurysm, however it demonstrated a left PTA originating from the cavernous ICA. Bykowski et al also reported a case of PTA (type IIIb) associated with a cerebellar infarct in a patient who presented with dysmetria and gait imbalance. Hwang et $a l^{6}$ reported a 39-year-old woman who presented with headache due to a subarachnoid haemorrhage. CTA and DSA revealed PTA variants (Saltzman type IIIb and type IIIc) with multiple cerebral aneurysms. We are reporting a very rare case of PTA Saltzman type IIIa associated with multiple cerebral aneurysms. 
It is important to be aware of this anatomical variant, given the risk of deviation of emboli in therapeutic endovascular procedures, potential risk of brain stem and cerebellar ischaemia, and risk of ischaemia and haemorrhage by surgical manipulation of these vessels with posterior fossa approaches. The blush seen in angiograms might also be misinterpreted as tumour or ischaemia. ${ }^{3}$

Whether the persistence of carotid-vertebrobasilar anastomosis predisposes patients to an increased risk of aneurysms remains a highly debatable point. Alteration of the haemodynamic flow is suspected to play a role. Kirkland et $\mathrm{al}^{7}$ presented a case of transclival artery with several aneurysms, including

\section{Patient's perspective}

I remember having a terrible headache before I went to the hospital. They diagnosed me with an aneurysm. I had two procedures done on me. I needed rehab initially but improved. A nurse came to visit me after I was discharged and was surprised to see me doing so well. The nurse thought I would end up in a wheelchair. I feel incredibly lucky to be walking again and thankful to have Dr Gould as my surgeon. I also wonder how many people have this similar anatomical variant. I feel like the prevalence might be higher than reported. I hope this report can help other people and doctors around the world.

\section{Learning points}

- Although rare, the persistent trigeminal artery can originate from the internal carotid artery and terminate in the superior cerebellar artery (Saltzman type IIIa) as an anatomical variant.

- Awareness of this anatomical variant will prevent incorrect diagnosis and possible complications from surgical procedures.

- Persistent carotid-vertebrobasilar anastomoses (particularly Saltzman type Illa variant) are possibly associated with an increased risk of aneurysm formation. aneurysms of the aortic arch, proximal basilar artery and A Comm. Literature review done by Yamamoto $e \mathrm{al}^{8}$ revealed that $26 \%$ (40 of 155) of cases with persistent hypoglossal arteries were found to have saccular intracranial aneurysms. The association between increased risk of intracranial aneurysms and PTA is still controversial. ${ }^{9}{ }^{10}$ Agnoli ${ }^{11}$ and George et al ${ }^{12}$ reported the prevalence of aneurysms in PTA to be $14 \%-32 \% .^{11} 12$

\section{Twitter Rashid Ahmed @Takanshooka}

Acknowledgements We would like to thank Dr. Neil Suryadevara for his inputs.

Contributors OA drafted the initial manuscript and acquired the images. RA reviewed and edited the manuscript. AE was involved in the critical revision of content. GG was involved in patient care, edited the manuscript and reviewed it for content.

Funding The authors have not declared a specific grant for this research from any funding agency in the public, commercial or not-for-profit sectors.

Competing interests None declared.

Patient consent for publication Not required.

Provenance and peer review Not commissioned; externally peer reviewed.

\section{REFERENCES}

1 Park SI, Kim DI, Jun P, et al. Persistent Carotid-Vertebrobasilar anastomosis: radiologic findings. J Korean Radio/ Soc 1998;39:863-7.

2 Uchino A, Kato A, Takase Y, et al. Persistent trigeminal artery variants detected by MR angiography. Eur Radiol 2000;10:1801-4.

3 Siqueira M, Piske R, Ono M, et al. Cerebellar arteries originating from the internal carotid artery. AJNR Am J Neuroradiol 1993;14:1229-35.

4 Shoja MM, Loukas M, Tubbs RS, et al. An aberrant cerebellar artery originating from the internal carotid artery. Surg Radiol Anat 2012;34:285-8.

5 Bykowski J, Jahan R, Pakbaz RS. Variant carotid origin of left anterior inferior cerebellar artery mimicking infarct on angiography. J Neurointerv Surg 2011;3:279-81.

6 Hwang YU, Kim JW. Variant PTA terminating in cerebellar artery, associated with multiple aneurysms. Case Rep Radiol 2016;2016:1-3.

7 Kirkland JD, Dahlin BC, O'Brien WT. The transclival artery: a variant persistent carotidbasilar arterial anastomosis not previously reported. J Neurointerv Surg 2017;9:e11.

8 Yamamoto S, Sunada I, Matsuoka Y, et al. Persistent primitive hypoglossal artery aneurysms--report of two cases. Neurol Med Chir 1991;31:199-202.

9 Cloft HJ, Razack N, Kallmes DF. Prevalence of cerebral aneurysms in patients with persistent primitive trigeminal artery. J Neurosurg 1999;90:865-7.

10 Diana F, Mangiafico S, Valente V, et al. Persistent trigeminal artery aneurysms: case report and systematic review. J Neurointerv Surg 2019;11:1261-5.

11 Agnoli AL. Vascular anomalies and subarachnoid haemorrhage associated with persisting embryonic vessels. Acta Neurochir 1982;60:183-99.

12 George AE, Lin JP, Morantz RA. Intracranial aneurysm on a persistent primitive trigeminal artery. Case report. J Neurosurg 1971;35:601-4.

Copyright 2021 BMJ Publishing Group. All rights reserved. For permission to reuse any of this content visit

https://www.bmj.com/company/products-services/rights-and-licensing/permissions/

BMJ Case Report Fellows may re-use this article for personal use and teaching without any further permission.

Become a Fellow of BMJ Case Reports today and you can:

- Submit as many cases as you like

- Enjoy fast sympathetic peer review and rapid publication of accepted articles

- Access all the published articles

Re-use any of the published material for personal use and teaching without further permission

Customer Service

If you have any further queries about your subscription, please contact our customer services team on +44 (0) 2071111105 or via email at support@bmj.com.

Visit casereports.bmj.com for more articles like this and to become a Fellow 